\title{
A case report on COVID-19 complicated with acute myocardial infarction, acute kidney injury and acute hepatitis
}

\author{
Rahim MA ${ }^{\mathrm{a}}$, Zaman $\mathrm{S}^{\mathrm{c}}$
}

\begin{abstract}
Outcome of coronavirus disease 2019 (COVID-19) is worse among elderly population, those with diabetes mellitus and other co-morbidities and such patients are prone to develop multiple complications. An elderly diabetic lady got admitted for acute myocardial infarction. Subsequent evaluation revealed a positive reverse transcriptase polymerase chain reaction (RT-PCR) for severe acute respiratory syndrome coronavirus 2 (SARS$\mathrm{CoV}-2)$, acute kidney injury, acute hepatitis and sepsis. She was managed accordingly and her post-discharge follow-up was satisfactory.
\end{abstract}

Key words: acute myocardial infarction, acute hepatitis, acute kidney injury, complication, COVID-19.

(BIRDEM Med J 2020; 10, COVID Supplement: 120-121)

\section{INTRODUCTION}

Since the onset of the outbreak of the coronavirus disease 2019 (COVIID-19), it has established as a multi-system disease, though initially it appeared to be respiratory one. It may cause abnormal clotting to result in acute myocardial infarction (AMI), stroke and limb ischaemia. ${ }^{1}$ Acute kidney injury (AKI) may result from such thrombosis and by many other mechanisms. ${ }^{1,2}$ Abnormal liver biochemistry is frequently observed in viral infections; severe acute respiratory syndrome coronavirus 2 (SARS-CoV-2) is not an exception. Patients with COVID-19 may be complicated by sepsis and multi-organ failure. Here, we report such a case with favourable outcome.

\section{CASE REPORT}

A 64-year-old lady, diagnosed with type 2 diabetes mellitus, presented at nephrology outpatient department

\section{Author information}

a. Muhammad Abdur Rahim, Associate Professor, Department of Nephrology, BIRDEM General Hospital, Dhaka, Bangladesh.

b. Shahana Zaman, Assistant Professor, Department of Cardiology, NICVD, Dhaka, Bangladesh.

Address of correspondence: Muhammad Abdur Rahim, Associate Professor, Department of Nephrology, BIRDEM General Hospital, Dhaka, Bangladesh. Email: muradrahim23@yahoo.com

Received: November 15, 2020

Revision received: November 20, 2020

Accepted: December 15, 2020 of a tertiary care hospital for follow-up on October 26, 2020, following discharge from a COVID-dedicated hospital for evaluation of resolving AKI. She was anaemic ( $\mathrm{Hb} 7.7 \mathrm{~g} / \mathrm{dl})$, her serum creatinine fell to 1.4 $\mathrm{mg} / \mathrm{dl}$ (which was $2.7 \mathrm{mg} / \mathrm{dl}$ during discharge) and urine routine and microscopic examinations revealed plenty of pus cells/high power field. A urine culture was requested.

She first got admitted in coronary care unit of the same hospital on August 25, 2020 with chest pain and shortness of breath. Cardiac evaluation revealed acute myocardial infarction (AMI) (inferior) with right ventricular (RV) infarction. Thrombolysis was done with streptokinase. As part of routine screening, reverse transcriptase polymerase chain reaction (RT-PCR) for COVID-19 was done and appeared positive. She had raised serum creatinine $(2.3 \mathrm{mg} / \mathrm{dl})$ and altered liver biochemistry (serum bilirubin $2.9 \mathrm{mg} / \mathrm{dl}$, alanine aminotransferase $3353 \mathrm{U} / \mathrm{L}$, aspartate aminotransferase $2760 \mathrm{U} / \mathrm{L}$, prothrombin time $24.5 \mathrm{sec}$, control $12 \mathrm{sec}$.). She had raised C-reactive protein $(164 \mathrm{mg} / \mathrm{L}$, ref $<6)$ and D-dimer $(3499 \mathrm{ng} / \mathrm{ml}$, ref. $<500)$ levels.

Patient was referred to a COVID-dedicated hospital with a diagnosis of COVID-19, AMI (inferior with RV extension) and sepsis with multi-organ failure, where she was further evaluated by high resolution computed 
tomography (HRCT) scan of chest, which revealed bilateral ground glass opacity (GGO). There she had been managed following national guidelines and she was discharged on September 13, 2020 with advice for follow-up at renal outpatients.

\section{DISCUSSION}

SARS-CoV-2 enters in to human body after binding with angiotensin receptor type 2 (ACE2), which is widely expressed throughout the body. Thus, it is now better understood that COVID-19 is not only a disease of respiratory system, rather it is a multi-system disease.

Abnormal coagulation appeared as an important feature of COVID-19 in May 2020, when a series of autopsy findings described intrapulmonary clots from Germany. ${ }^{3}$ After discovery of these findings, many authorities included low molecular weight heparin for hospitalized COVID-19 patients and patients with comorbidities. ${ }^{4}$

Clots give rise to some unique features for COVID-19, depending up on size and location of vessels. It can lead to stroke or transient ischaemic attacks, acute coronary syndrome ${ }^{5}$, ischaemic limbs and so on. COVID toe, a Kawasaki disease like entity is being reported. ${ }^{1}$

One-fifth of COVID-19 patients were reported as being complicated by AKI. ${ }^{5}$ AKI in COVID-19 patients may result from multiple insults; may be pre-renal from dehydration, vomiting, diarrhea, may be a result of concomitant septic shock, renal vascular thrombosis or direct viral invasion. Viral particles have been stained in renal biopsy specimens and recovered from urines. ${ }^{1}$

Abnormal transaminase levels were observed in series of COVID-19 cases and Wander P et al reported first case of asymptomatic COVID-19 with hepatitis. ${ }^{6}$ The present case had further higher levels of hepatic enzymes, may be compounded by RV infarction and hepatic congestion.
Outcome of COVID-19 is worse among elderly patients, those with diabetes mellitus and other co-morbidities. Outcome becomes worse with numbers of organ involvements; but that is not the end of story. Proper, timely, symptomatic and supportive therapy may result in favourable outcome, as in the case presented here.

Authors' contribution: MAR followed up the case, did literature search and drafted the manuscript. SZ did echocardiographic follow up of the patient. Both authors read and approved the final manuscript for submission.

Conflicts of interest: Nothing to declare.

\section{REFERENCES}

1. Gupta A, Madhavan MV, Sehgal K, Nair N, Mahajan S, Sehrawat TS, et al. Extrapulmonary manifestations of COVID19.

2. Juthani P, Bhojwani R, Gupta N. Coronavirus Disease 2019 (COVID-19) Manifestation as Acute Myocardial Infarction in a Young, Healthy Male. Case Reports in Infectious Diseases 2020; Article ID 8864985, 4 pages. https://doi.org/10.1155/ 2020/8864985.

3. Wichmann D, Sperhake J-P, Lu“ tgehetmann M, Steurer S, Edler C, Heinemann A, et al. Autopsy Findings and Venous Thromboembolism in Patients with COVID-19: A Prospective Cohort Study. Ann Intern Med 2020 May 6: M20-2003. Published online 2020 May 6. doi: 10.7326/M20-2003

4. Disease Control Division. Directorate General of Health Services. Ministry of Health \& Family Welfare. Government of the People's Republic of Bangladesh. National Guidelines on Clinical Management of Coronavirus Disease 2019 (COVID-19). Version 7.0. Published, 28 May 2020.

5. Cui X, Yu X, Wu X, Huang L, Tian Y, Huang X, et al. Acute Kidney Injury in Patients with the Coronavirus Disease 2019: A Multicenter Study. Kidney Blood Press Res 2020; 45: 61222 .

6. Wander P, Epstein M, Bernstein D. COVID-19 Presenting as Acute Hepatitis. Am J Gastroenterol 2020; 00: 1-2. https:// doi.org/10.14309/ajg.0000000000000660 